\title{
Clinical case of pregnancy toxaemia in a goat - a case report on veterinary medicine approach
}

\begin{abstract}
A pregnant Jamnapari doe was presented with primary complaint of inappetance and recumbency for a week. The most prominent abnormality during physical examination was weakness in both hind limbs typified by difficulty in standing. Ultrasonography revealed that the doe were carrying three viable foetuses that were about 4-months old. Hematobiochemistry findings showed hypocalcaemia $(1.98 \mathrm{mmol} / \mathrm{L})$ and hypoglycaemia $(2.2 \mathrm{mmol} / \mathrm{L})$. Besides that, ketone bodies were also detected from the urine $(3+$ or $8 \mathrm{mmol} / \mathrm{L})$. The doe was treated vigorously for pregnancy toxaemia with 1L of Glucose $20 \%$ (G-20) and $5 \mathrm{~L}$ of $0.9 \% \mathrm{NaCl}$, administered intravenously BID for 3 days as glucose replacement and rehydration respectively. $30 \mathrm{~mL}$ of propylene glycol was also given orally BID for 7 days as glucose precursor. Flunixin meglumine $2.2 \mathrm{mg} / \mathrm{kg}$ was administered intramuscularly SID for 3 days as non-steroidal anti-inflammatory. In addition, $20 \mathrm{~mL}$ of theracalcium was given intramuscularly SID for two days and $5 \mathrm{~mL}$ of Catosal ${ }^{\circledR}$ was given intramuscularly SID for 6 days for calcium supplement and to stimulate body metabolism respectively. One vial $(2 \mathrm{ml})$ of methylcobalt was administered intramuscularly SID for 3 days as a nerve supplement and physiotherapy was performed after caesarean section for 10 minutes TID for 6 days in order to increase blood circulation and prevent muscle atrophy. However, the does' condition started to deteriorate on Day 7 and caesarean was performed on the same day where three foetuses were saved. The doe's condition improved tremendously and was discharged after a week of caesarean section. This clinical case reports the clinical management of pregnancy toxaemia in a goat, which is a common problem in small holder farms in Malaysia.
\end{abstract}

Keyword: Doe; Pregnancy toxaemia; Clinical management; Treatment 
